\title{
Patients Returning to Dialysis after Failed Kidney Transplant: How Do They Fare? A Gulf Perspective
}

\author{
Samra Abouchacra1, Ahmed Chaaban', Abdelkarim Saleh"2, Muna Rukhaimi ${ }^{3}$, \\ Osman Furaih4, Naveed Haq4, Mohamed Osman', Nicole Gebran1, Qutaiba Hussain"1, \\ Fares Chedid1, Mohammad Budruddin'1, Suad Sajwani1 \\ ${ }^{1}$ Department of Nephrology, Tawam Hospital, Al Ain, UAE \\ ${ }^{2}$ Department of Nephrology, Sheikh Khalifa Medical City, Abu Dhabi, UAE \\ ${ }^{3}$ Department of Nephrology, Dubai Hospital, Dubai, UAE \\ ${ }^{4}$ Department of Nephrology, King Faisal Specialist Hospital and Research Center, Riyadh, KSA \\ Email: sabouchacra@tawamhospital.ae
}

Received 14 July 2014; revised 11 August 2014; accepted 3 September 2014

Copyright (C) 2014 by authors and Scientific Research Publishing Inc.

This work is licensed under the Creative Commons Attribution International License (CC BY).

http://creativecommons.org/licenses/by/4.0/

(c) (i) Open Access

\begin{abstract}
An increasing number of failed transplant patients returning to dialysis (FTRD) have been observed with reported worse survival compared to transplant-naive dialysis (TxN) patients. This study aimed to assess outcomes of FTRD vs. matched TxN controls in a Gulf region multi-center trial of 800 HD patients. Similar mortality was seen, likely due to earlier start and better HD adequacy in FTRD. Younger age, less diabetes and living donor transplantation in majority with $\mathbf{2 7 \%}$ graft nephrectomy (Nx) might also confer benefits. Subgroup analysis of Nx patients showed more hospitalizations and prior rejection episodes with lower graft survival. The deaths, however, occurred only in nonNx group and are likely explained by older age, longer duration on HD, more prevalence of diabetes and CAD. FTRD showed similar survival to TxN. Early intensive HD might account for the benefit. Whether Nx confers advantage is unclear because of the small sample size.
\end{abstract}

\section{Keywords}

Renal Transplant, Graft Nephrectomy, Hemodialysis Dialysis, Transplant-Naive Patients, End Stage Renal Disease, ESRD

\section{Introduction}

There is an increasing number of patients with failed kidney transplant reentering dialysis programs (FTRD) [1], How to cite this paper: Abouchacra, S., Chaaban, A., Saleh, A., Rukhaimi, M., Furaih, O., Haq, N., Osman, M., Gebran, N., Hussain, Q., Chedid, F., Budruddin, M. and Sajwani, S. (2014) Patients Returning to Dialysis after Failed Kidney Transplant: How Do They Fare? A Gulf Perspective. Open Journal of Internal Medicine, 4, 82-86. 
reported at $2 \%$ - $3 \%$ per annum [2]. This is primarily attributed to persistently poor long-term graft survival despite major advances in immune suppressive therapy [3] with annual graft failure rates of $4 \%$ [4] [5]. This translates into an ever-increasing prevalence rate of FTRD patients. In fact, currently they seem to constitute almost $20 \%$ of wait-listed individuals [3].

Interestingly, this group of patients appears to be unique in terms of their survival on dialysis with conflicting reported outcome studies. Not surprisingly, when compared to patients with continued graft function, FTRD patients exhibit reduced survival [6] with three times greater USRDS annual adjusted death rate [6]. However, it is their survival compared to transplant naïve dialysis patients, which has been the source of serious controversy [7] [8]. Few observational studies have reported worse survival among FTRD patients [9] [10] but most were smallsized studies with methodological problems. On the other hand, similar mortality as in transplant-naïve patients has been observed by Akbari [11] and also reported by the Canadian Organ Replacement Register (CORR) [7]. The latter data however were [7] confounded by inclusion of non wait-listed patients in the control group with bias towards less favorable survival, a finding confirmed by others [11]. In a subsequent analysis by Rao [8] which included only wait-listed transplant-native patients, 78\% greater mortality was seen in FTRD patients up to 10 years post graft loss. This was reproduced by Fresnedo [9], showing increased mortality at 1 and 5 years related to cardiovascular and infectious complications [12].

The aim of this multicenter study was to assess the outcomes of End Stage Renal Disease (ESRD) patients starting dialysis after failed kidney transplant in our region and recognize factors impacting such outcomes.

\section{Patients \& Methods}

In this multicenter retrospective analysis, subjects were included who had failed kidney transplant and re-entered dialysis programs having previously been on hemodialysis or peritoneal dialysis for at least six months with mean follow up of 36 months. The study was performed in tertiary care medical centers in the Arab Gulf between 2007 and 2009. Demographic information was gathered regarding age, sex, co morbidities, cause of ESRD, duration of dialysis prior to transplantation, transplant survival duration, immunosuppressive agents, and number of episodes of rejection. Their outcome on dialysis was assessed and compared to matched historical controls on Hemodialysis, those having never been transplanted. Parameters evaluated by laboratory blood tests included: hemoglobin, albumin, KT/V, CRP, ferritin, iron level, erythropoietin dose, intact PTH, vascular access type, residual glomerular filtration rate. Mortality was our study's primary outcome. A further subgroup analysis was undertaken to evaluate FTRD patients who underwent graft nephrectomy with regards to these outcome measures as well as rate of re-transplantation.

\section{Statistical Analysis}

The statistical analysis was performed using SPSS 20.0 (Chicago, USA). Continuous data were compared using 2 samples t-test or Mann Whitney U-test as appropriate. Categorical data were compared within Chi Square test or Fisher exact test. The results were considered significant when p-value was below 0.05 .

\section{Results}

The FTRD group consisted of 55 patients, the majority of whom received living non-related renal transplant (46); 2 were transplanted for the second time. The remaining received cadaveric (2) and living related transplants (7). All were treated with CNI based immune suppression combined with azathioprine or MMF and steroids. Episodes of acute rejection were reported in 18 patients with mean graft survival of 93.84 (66.61) months. Causes of allograft failure included CAN (38), non-compliance with meds (5), sepsis (1), obstructive uropathy (1), vascular rejection (2) and unknown (8). The average duration on dialysis prior to transplantation was 35.81 (34.39) months with a range of 3 - 168 months. The majority had been on hemodialysis (53) versus peritoneal dialysis (2). Mean BMI for the group was 25.35. Once back on dialysis following graft failure, all were undergoing three times weekly hemodialysis sessions with an average duration of 4 hours, similar to transplant naive patients. The demographic data and outcome parameters for both groups are shown in Table 1.

Within the FTRD group, further analysis was performed comparing the outcomes of those with insitu allograft versus nephrectomized patients. The demographics of both groups and their outcome measures are shown in Table 2. 
Table 1. Outcome parameters in FTRD vs. TXN.

\begin{tabular}{|c|c|c|c|}
\hline & FTRD (55) & TN (52) & p-Value \\
\hline Mean Age (yrs) & $47.20(12.06)$ & $50.4(8.13)$ & NS \\
\hline M:F & $38: 17$ & $35: 17$ & NS \\
\hline Renal Disease-GN: DM: & (21):6 & (2):14 & $0.0001^{*}$ \\
\hline HTN: OBST & $7: 2$ & $2: 1$ & NS \\
\hline Familial: unknown & $3: 16$ & $0: 33$ & $0.049^{*}$ \\
\hline Mean post Tx hemodialysis (months) & $36.63(29.3)$ & $31.53(29.7)$ & NS \\
\hline $\mathrm{KT} / \mathrm{V}$ & $1.62(0.84)$ & $1.29(0.12)$ & $0.006^{*}$ \\
\hline Albumin $g / l$ & $33.79(5.76)$ & $37.45(5.4)$ & $0.001^{*}$ \\
\hline $\mathrm{Hb} \mathrm{g/l}$ & $11.39(5.76)$ & $11.99(1.15)$ & NS \\
\hline Ferritin mcg/l & $341(342)$ & $367(250)$ & NS \\
\hline $\mathrm{CRP} \mathrm{mg} / \mathrm{l}$ & $33.94(26.04)$ & $9.14(0.33)$ & $0.0001^{*}$ \\
\hline $\mathrm{PTH} \mathrm{pmol} / \mathrm{l}$ & $112.50(86.91)$ & $61.23(35.37)$ & $0.0002^{*}$ \\
\hline S calcium & $2.10(0.35)$ & $2.22(0.14)$ & NS \\
\hline S PO4 & $1.59(0.48)$ & $1.53(0.53)$ & NS \\
\hline Ave EPO/wk (IU) & $9820(5756)$ & $5584(4063)$ & $0.001^{*}$ \\
\hline eGFR at start $\mathrm{HD}(\mathrm{ml} / \mathrm{min})$ & $8.4(1.6)$ & $<5$ & NS \\
\hline Permcath: AVG: AVF & $18: 5: 32$ & $8: 2: 42$ & $0.04^{*}$ \\
\hline CAD & 9 & 6 & NS \\
\hline $\mathrm{HCV}$ & 20 & 6 & $0.001^{*}$ \\
\hline $\mathrm{HBV}$ & 2 & 1 & NS \\
\hline \# NX & $15(27 \%)$ & - & - \\
\hline Deaths & $2(3.6 \%)$ & $2(3.8 \%)$ & NS \\
\hline
\end{tabular}

${ }^{*} \mathrm{p}<0.05$ significant

Table 2. Subgroup analysis Nx vs. Non Nx: outcome measures.

\begin{tabular}{|c|c|c|c|}
\hline & NX (15) & Non NX (40) & p-Value \\
\hline Mean Age $44.92+11.8$ & $44.92(11.8)$ & $51.07(9.68)$ & NS \\
\hline M:F & $8: 7$ & $36: 4$ & $0.02^{*}$ \\
\hline Duration dialysis preTx (months) & $21.67(17.54)$ & $36.81(40)$ & NS \\
\hline Cause ESRD- GN: diabetes: hypertension: Familial: obstruction: unknown & 9:1:1:2:2:0 & $12: 5: 6: 1: 2: 14$ & NS \\
\hline \# Acute rejection & $6(40 \%)$ & $11(26 \%)$ & $0.01^{*}$ \\
\hline Graft survival (months) & $65.80(43.63)$ & $107.08(73.76)$ & NS \\
\hline RRF at HD start (ml/min) & $6.80(2.55)$ & $8.23(0.86)$ & NS \\
\hline Mean duration of dialysis post allograft failure (months) & $47(50)$ & $20.70(29)$ & $0.01^{*}$ \\
\hline $\mathrm{KT} / \mathrm{V}$ & $1.39(0.39)$ & $1.74(0.50)$ & NS \\
\hline Albumin (g/l) & $33.07(9.44)$ & 33.88 (3.88) & NS \\
\hline $\mathrm{Hb}(\mathrm{g} / \mathrm{l})$ & $11.86(2.10)$ & $11.15(1.57)$ & NS \\
\hline Ferritin (mcg/l) & $428(345)$ & 311.35 (347) & 0.05 \\
\hline PTH (pmol/l) & 51.85 (29) & $82.57(46)$ & NS \\
\hline CRP (mg/l) & 23.36 (31.98) & 30.71 (37.92) & NS \\
\hline Ave EPO/wk (IU) & 7543.80 (7629) & 11050 (7632) & NS \\
\hline HCV: HBV & $7: 0$ & $13: 2$ & NS \\
\hline Permcath: AVG: AVF & $3: 1: 11$ & $15: 1: 24$ & NS \\
\hline LVH: CAD & $3: 2$ & $5: 7$ & NS \\
\hline \# admissions & $5.75(2.06)$ & 3.86 (1.68) & NS \\
\hline \# reTx: deaths & $2: 0$ & $0: 2$ & NS \\
\hline
\end{tabular}

${ }^{*} \mathrm{p}<0.05$ significant 


\section{Discussion}

Despite more co morbidities (coronary artery disease, hepatitis B, C) in FTRD group and the attendant risk of immune suppressives, similar mortality was observed compared to controls. This is especially significant since the control group included many potential waitlist candidates favoring better survival. Our results are in contrast to those reported by Rao [8] and Fresnedo [9] both of whom showed greater short and long term mortality rate in FTRD compared to waitlisted transplant naive patients. Cardiovascular disease and infections have been ranked the highest as causes for the increased risk [12] attributed to poor predialysis control of chronic kidney disease CKD complications and comorbid conditions as well as persistent chronic inflammatory state [6] [9] [12] [13]. Conversely, the more favorable overall survival in our patients may likely be related to fewer diabetics and relatively younger age in the FTRD group, though latter was not statistically significant. This might also be explained by, perhaps better predialysis and dialytic management, providing care by transplant nephrologists and earlier initiation of dialysis with an average eGFR of $8.4 \mathrm{ml} / \mathrm{min}$. The earlier start of HD and nephrologistdelivered predialysis care has been suggested by Rao [7] to offer a survival advantage in FTRD. Moreover, the majority of our patients had received LNRT, the outcome of which is better than cadaveric.

Of note, however, the FTRD group had lower serum albumin, higher PTH levels and evidence of ongoing inflammation with increased CRP and erythropoietin requirement. The latter suggesting Epo-resistance which has been reported [14] likely due to the presence of immunologically active allograft. Unexpectedly however, the serum ferritin was not statistically increased in FTRD patients. Those patients additionally had more vascular access problems suggested by the greater prevalence of permacath probably from repeat blood sampling.

Importantly however, $27 \%$ of our failed transplant patients had undergone graft nephrectomy. Though there are reports of survival benefit [15] likely through elimination of the chronic inflammatory state and need for ongoing immune suppression. On the other hand, this potentially counters the survival advantage conferred by presence of residual renal function. Hence its impact on survival remains unclear.

To explore this further, subgroup analysis of $\mathrm{Nx}$ vs. nonNx patients was undertaken with results shown in Table 2. Our Nx patients had lower graft survival and more episodes of acute rejection perhaps suggesting early or severe rejection. As expected, the absence of immunologically active graft led to lower CRP and Epo requirement, in Nx group however their ferritin levels were higher, though of borderline statistical significance. Serum albumin and Hb were similar but PTH levels were insignificantly higher in non Nx despite shorter duration on HD following graft loss. Though both groups had significant access complications with many dialyzed through permacath, the Nx group had an insignificant greater number of admissions despite less immune suppression but our numbers are small and data did not differentiate between infectious vs. noninfectious hospitalizations. With respect to the main outcome measure, the 2 deaths occurred in non Nx patients were due to cardiovascular causes and may likely be explained by older age, longer duration on HD, more prevalence of diabetes and coronary artery disease (CAD). Unexpectedly retransplantation took place only in Nx group despite the known immune modulatory effect of insitu allograft. It is difficult however, to draw any firm conclusions given our small sample size and retrospective nature of our study.

\section{Conclusion}

Similar survival in FTRD and TxN patients has been observed adding to the controversy surrounding their outcome and the reference group to whom they should be compared. Nevertheless, intensive pre dialysis care and early initiation of dialysis seem advantageous. Questions remain as to the benefit of maintenance immune suppression for preservation of residual allograft function and induction of immune tolerance versus nephrectomy which eliminates the chronic inflammatory state and obviates the need for immune suppressives. Our Nx patients appeared to have better survival but more hospitalizations compared to non Nx group however it is difficult to draw conclusions given the small sample size. Physicians must therefore evaluate each case individually.

\section{References}

[1] Perl, J., Bargman, J.M., Davies, S.J., et al. (2008) Clinical Outcomes after Failed Renal Transplantation-Does Dialysis Modality Matter? Seminars in Dialysis, 21, 239-244. http://dx.doi.org/10.1111/j.1525-139X.2008.00441.x

[2] CORR Preliminary Report (2002) Preliminary Statistics for Renal Failure and Solid Organ Transplantation in Canada. Canadian Organ Replacement Register, Ottawa, 2193-2200. 
[3] Meier-Kriesche, H.U., Schold, J.D. and Kaplan, B. (2004) Long Term Allograft Survival: Have We Made Significant Progress or Is It Time to Rethink Our Analytic and Therapeutic Strategies? American Journal of Transplantation, 4, 1289-1295. http://dx.doi.org/10.1111/j.1600-6143.2004.00515.x

[4] United States Renal Data System (2007) Chapter Seven. Transplantation.

[5] Rockville, M.D., Richmond, V.A. and Ann Arbor, M.I. (2004) 2004 Annual Report of the US Organ Procurement and Transplantation Network and the Scientific Registry of Transplant Recipients.

[6] Meier-Kriesche, H.U. and Kaplan, B. (2001) Death after Graft Loss: A Novel Endpoint for Renal Transplantation. Transplantation Proceedings, 33, 3405-3406. http://dx.doi.org/10.1016/S0041-1345(01)02467-8

[7] Rao, P.S., Schaubel, D.E. and Saran, R. (2005) Impact of Graft Failure on Patient Survival on Dialysis: A Comparison of Transplant-Naive and Post-Graft Failure Mortality Rates. Nephrology Dialysis Transplantation, 20, 387-391. http://dx.doi.org/10.1093/ndt/gfh595

[8] Rao, P.S., Schaubel, D.E., Jia, X., et al. (2007) Survival on Dialysis Post-Kidney Transplant Failure: Results from the Scientific Registry of Transplant Recipients. American Journal of Kidney Diseases, 49, 294-300. http://dx.doi.org/10.1053/j.ajkd.2006.11.022

[9] Fresnedo, G.F., Ruiz, J.C., Alamillo, C.G., et al. (2008) Survival after Dialysis Inititation: A Comparison of Transplant Patients after Graft Loss versus Nontransplant Patients. Transplantation Proceedings, 40, 2889-2890. http://dx.doi.org/10.1016/j.transproceed.2008.08.094

[10] Sleiman, J., Garrigue, V., Vetromile, F., et al. (2007) Return to Dialysis after Renal Allograft Loss: Is Dialysis Treatment Initiated too Late? Transplantation Proceedings, 39, 2597-2598. http://dx.doi.org/10.1016/j.transproceed.2007.08.030

[11] Akbari, A., Hussain, N., Karpinski, J., et al. (2007) Chronic Kidney Disease Management: Comparison between Renal Transplant Recipients and Nontransplant Patients with Chronic Kidney Disease. Nephron Clinical Practice, 107, c7c13. http://dx.doi.org/10.1159/000105138

[12] Gill, J.S., Abichandani, R., Kausz, A.T., et al. (2002) Mortality after Kidney Transplant Failure: The Impact of Non-Immunologic Factors. Kidney International, 62, 1875-1883. http://dx.doi.org/10.1046/j.1523-1755.2002.00640.x

[13] Ansell, D., Udayaraj, U.P., Steenkamp, R., et al. (2007) Chronic Renal Failure in Kidney Transplant Recipients. Do They Receive Optimum Care? Data from the UK Renal Registry. American Journal of Transplantation, 7, 1167-1176. http://dx.doi.org/10.1111/j.1600-6143.2007.01745.x

[14] Solid, C.A., Foley, R.N., Gill, J.S., et al. (2007) Epoetin Use and Kidney Disease Outcomes Quality Initiative Hemoglobin Targets in Patients Returning to Dialysis with Failed Renal Transplants. Kidney International, 71, 425-430. http://dx.doi.org/10.1038/sj.ki.5002056

[15] Ayus, J.C., Achinger, S.G., Shuko, L., et al. (2010) Tranplant Nephrectomy Associates with Improved Survival in Patients with Failed Renal Allograft. Journal of the American Society of Nephrology, 21, 374-380. http://dx.doi.org/10.1681/ASN.2009050480 
Scientific Research Publishing (SCIRP) is one of the largest Open Access journal publishers. It is currently publishing more than 200 open access, online, peer-reviewed journals covering a wide range of academic disciplines. SCIRP serves the worldwide academic communities and contributes to the progress and application of science with its publication.

Other selected journals from SCIRP are listed as below. Submit your manuscript to us via either submit@scirp.org or Online Submission Portal.
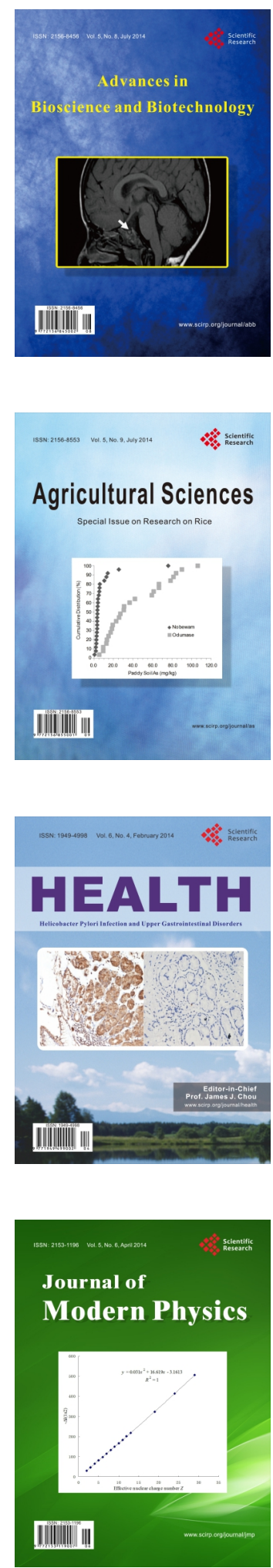
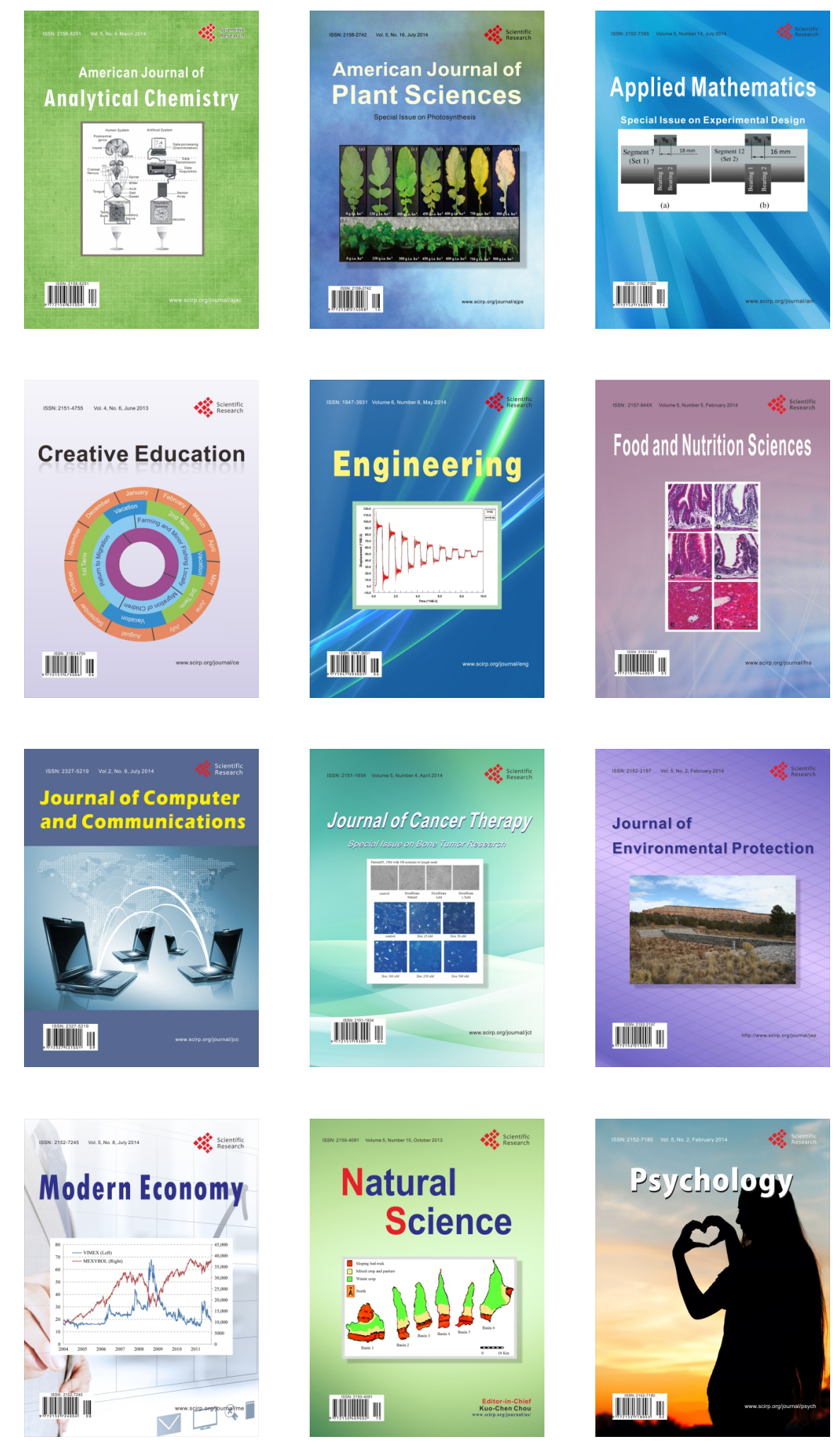